\title{
Excess capacity and asymmetric information in developing country fisheries: the Malaysian purse seine fishery
}

\begin{abstract}
Excess capacity poses a problem in many developing country fisheries. These countries often pursue a development strategy aimed at expanding capacity under open access. Sustainable development, however, requires management. Principal-agent issues from asymmetric information between the regulator and fishers, which potentially form serious obstacles to fisheries management, arise in the likely forms of management. This article discusses principal-agent issues and examines the principal-agent moral hazard issue, which is due to divorce of ownership and vessel operations. The article also illustrates a method for estimating capacity when information is limited. The Peninsular Malaysian purse seine fishery forms a case study.
\end{abstract}

Keyword: Capacity; Data envelopment analysis; Principal-agent; Technical efficiency 